Journal of Healthcare Technology and Medicine Vol. 2 No. 2 Oktober 2016

Universitas Ubudiyah Indonesia

e-ISSN : 2615-109X

\title{
Hubungan Antara Pola Asuh Dan Status Ekonomi Dengan Status Gizi Anak Di Sekolah Dasar Negeri Uleegle
}

\author{
The Relationship Between Parenting and Economic Status with the Nutrition \\ Status of Children in Uleegle Public Primary School \\ ${ }^{1}$ Mira Abdullah, ${ }^{2}$ Elly Ratna Sari \\ ${ }^{1,2}$ Fakultas Ilmu Kesehatan, Universitas Ubudiyah Indonesia, Banda Aceh \\ Email: miraabdullah@uui.ac.id
}

\begin{abstract}
ABSTRAK
Masalah gizi pada usia sekolah dapat menyebabkan rendahnya kualiatas tingkat pendidikan, tingginya angka absensi dan tingginya angka putus sekolah, penyebab gizi kurang dipengaruhi oleh faktor langsung yaitu pola asuh, dan faktor tidak langsung status ekonomi. Untuk mengetahui Hubungan Antara Pola Asuh Dan Status Ekonomi Dengan Status Gizi Anak Sekolah Dasar Negeri Ulee Gle. Penelitian ini bersifat analitik, dengan populasi 164 siswa, dalam penelitian ini jumlah sampel sebanyak 62 siswa. Tehnik pengambilan sampel adalah Random Sampling. Pengumpulan data dilakukan dengan cara mengukur TB,BB dan membagikan kuisioner. Penelitian ini dilakukan disekolah dasar SD Negeri Ulee Gle mulai tanggal 12 Desember s.d. 17 Desember 2016, dari hasil penelitian menunjukkan. Bahwa hasil dari 62 responden yang diteliti terdapat hubungan antara pola asuh makan dengan status gizi anak sekolah dasar dimana $\mathrm{p}$-value $=0,024<0,05$ dan juga Ada hubungan status ekonomi dengan status gizi anak sekolah dasar dimana p-value 0,07<0,05. Di harapkan kepada para institusi pendidikan,responden, pihak sekolah, dan praktisi kesehatan agar terus meningkatkan pelayanan kesehatan terutama tentang status gizi anak sekolah dasar. Karena status gizi dapat memicu kecerdasan pada anak.
\end{abstract}

\section{Kata Kunci : Pola asuh, status ekonomi, status gizi anak sekolah dasar}

\begin{abstract}
Nutrition problems at school age can cause low levels of education, high absenteeism and high dropout rates, the cause of malnutrition is influenced by direct factors namely parenting, and indirect factors of economic status. To find out the relationship between parenting and economic status with the nutritional status of Ulee Gle elementary school children. This research is analytic, with a population of 164 students, in this study a total sample of 62 students. The sampling technique is random sampling. Data collection was carried out by measuring TB, BB and distributing questionnaires. This research was conducted at elementary school Ulee Gle State Elementary School starting on December 12 to December 17, 2016, the results of the study showed. That the results of the 62 respondents studied there is a relationship between eating patterns with the nutritional status of elementary school children where the p-value $=0.024<0.05$ and also there is a relationship of economic status with the nutritional status of elementary school children where the p-value $0.07<0.5$. It is expected that educational institutions, respondents, schools, and health practitioners will continue to improve health services, especially regarding the
\end{abstract}


Journal of Healthcare Technology and Medicine Vol. 2 No. 2 Oktober 2016

Universitas Ubudiyah Indonesia

e-ISSN : 2615-109X

nutritional status of elementary school children. Because nutritional status can trigger intelligence in children.

Keywords: Parenting, economic status, nutritional status of elementary school children

\section{PENDAHULUAN}

Indonesia mempunyai masalah gizi yang cukup berat yang ditandai dengan banyaknya kasus gizi kurang pada anak balita dan usia masuk sekolah baik pada laki-laki dan perempuan. Masalah gizi pada usia sekolah dapat menyebabkan rendahnya kualiatas tingkat pendidikan, tingginya angka absensi dan tingginya angka putus sekolah (Darwin,2008).

Kekurangan gizi pada anak sekolah akan mengakibatkan anak menjadi lemah, cepat lelah dan mudah sakit. Oleh karena itu anak-anak seringkali absen serta mengalami kesulitan dalam mengikuti dan memahami pelajaran. Dalam keadaan seperti itu sulit mewujudkan SDM yang sehat, cerdas, aktif, kreatif dan produktif yang mampu berkiprah dan bersaing pada era globalisasi( Notoatmodjo,2008).

Berdasarkan Data Riset Kesehatan Dasar (Riskesdas) pada tahun 2010 menunjukkan bahwa masih terdapat anak usia sekolah dasar yang prevalensi status gizinya (IMT/U) dengan kategori gizi kurang dan pendek menurun menjadi masing-masing 17,9\% dan 35,6\%. (Riskesdes,Depkes,2010). Berdasarkan data SD/MI dari dinas kesehatan pidie jaya tahun 2013 gizi normal sebanyak 63,6\%, gizi gemuk 17,9\%. Dan gizi kurus 18,4\%. Dan menurut data SD/MI yang didapat dari puskesmas Bandar Dua tahun 2013 terdapat 10,4\% gizi normal, 6,51\% gizi gemuk dan 16,9\% gizi kurus. Berdasarkan data tahun 2014 yang diperoleh peneliti dari puskesmas bandar dua bahwa di SD Negeri Ulee Gle terdapat 1,8\% gizi normal, 1,5\% gizi gemuk, dan $2.4 \%$ gizi kurus.

Berdasarkan Penelitian yang pernah dilakukan oleh Kodyat (2008) menunjukkan bahwa $57,3 \%$ anak sekolah dasar yang berstatus gizi baik, tidak mengalami gangguan pertumbuhan. Sedangkan sisanya mengalami gangguan partumbuhan tingkat sedang $(31,5 \%)$ dan tingkat kurang $11,2 \%$. Gangguan pertumbuhan pada anak SD ini juga ditemukan dengan prevalensi KEP ter- tinggi di Aceh 46,6\% dan Timtim 46,2\% sedangkan provinsi dengan pre- valensi terendah adalah Bali $(20,6 \%)$, di Yogya (18,9\%) dan DKI Jakarta (23\%). Rata - rata prevalensi KEP pada anak sekolah dasar di Indonesia adalah 26,3-29,9\%.

\section{METODOLOGI PENELITIAN}

Pengumpulan data dilakukan di disekolah dasar SD Negeri Ulee Gle dengan jenis penelitian bersifat deskriptif analitik dengan menggunakan desain Cross sectional dan uji bivariat chi square dengan CI (Confident Interval) 95\%. Analisa data menggunakan program statistik SPSS versi 17.0. Pengumpulan data dilakukan pada tanggal mulai tanggal 12 Desember s.d. 17 Desember 2016. Populasi 164 siswa, dalam penelitian ini jumlah sampel sebanyak 62 siswa. Tehnik pengambilan sampel adalah Random Sampling.

\section{HASIL DAN PEMBAHASAN}


Journal of Healthcare Technology and Medicine Vol. 2 No. 2 Oktober 2016

Universitas Ubudiyah Indonesia

e-ISSN : 2615-109X

\section{Hubungan Pola Asuh Dengan Status Gizi}

Pola asuh adalah kemampuan masyarakat untuk menyediakan waktu, perhatian dan dukungandalam memenuhikebutuhan fisik, mental, dan sosial dari anak yang sedang tumbuh dalam anggota keluarga lainnya. Pola asuh dimanifestasikan dalam 3 hal yaitu (1) pemberian makanan pada anak, (2) praktek kebersihandan sanitasi lingkungan (3) perawatan anak dalam keadaan sakit meliputi praktek kesehatan dirumah dan pola pencarian pelayanan kesehatan (Sunarti, 2000).

Menurut Depkes RI (2000), pola asuh adalah kemampuan seseorang untuk mengambil keputusan yang berdampak luas pada kehidupan seluruh anggota keluarga yang menjadi dasar penyediaan pengasuhan yang tepat dan bermutu pada anak termasuk pengasuhan makanan bergizi.

Pola asuh praktek pemberian makan yang baik sangat mendukung tercapainya status gizi anak yang baik. Apabila anak ditemukan dengan status gizi buruk pada praktek pemberian makan baik kemungkinan disebabkan karena perawatan kesehatan anak yang tidak baik, juga imunisasi tidak lengkapsehingga anak mudah terserang penyakit dan dapat saja terjadi kekurangan gizi. Praktek pemberian makan yangtidak baikditemukan anakstatus gizibaik. Hal ini, terjadi karena baik tidaknya status gizi anak dipengaruhioleh konsumsi makanan dan kesehatan. Dalam praktek pemberian makan anak tidak baik, kemungkinan didukung olehperawatan dankesehatan anakbaik makadapat menyebabkan status gizi baik

Menurut asumsi peneliti pola asuh yang baik sangat mendukung tercapainya status gizi anak yang baik, apabila pola asuh tidak baik anak mudah terserang penyakit sehingga dapat meningkatkan angka absensidi sekolah dan dengan maningkatnya angka absensi di sekolah dapat pula berpangaruh terhadap prestasi anak dalam belajar, untuk demikian kepedulian orang tua terhadap pola asuh anak sangat berperan dalam menyiapkam makanan dan bagaimana cara menyikapi anak yang tidak menyukai jenis makanan.Dari hasil penelitian yang peneliti dapatkan di lapangan bahwa kesibukan seorang ibu dalam berkerja sehingga ibu tidak dapat menyiapkan makanan untuk anak-anak nya. Sehingga memilih untuk jajan di sekolah atau di tempat penjual jajanan lain nya.

\section{Hubungan Status Ekonomi Dengan Status Gizi}

Penghasilan keluarga yang rendah merupakan variabel yang saling berinteraksi terhadaptimbulnya masalah gizi kurang. Di satu sisi kepala keluarga berusaha agar setiap anggota keluarga memperoleh pangan yang cukup, namun kepala keluarga mempunyai keterbatasan untuk memenuhi kebutuhan tersebut. Hal ini merupakan fenomena sosial yang harus diperhatikan bersama, setidak-tidaknya diperlukan uluran tangan darimultisektor untuk mengatasinya. Apabila kejadian ini terjadi berlanjut lama pada sebagian penduduk yang berdomisili di daerahterkenatsunami yang dihimpit oleh kemiskinan maka masa depan anak terganggusehingga pertumbuhan dan perkembangananak balita akan menjadi masalah dimasa yang akan datang. 
Journal of Healthcare Technology and Medicine Vol. 2 No. 2 Oktober 2016

Universitas Ubudiyah Indonesia

e-ISSN : 2615-109X

Menurut Sulistijani (2001), mengemukan seiring dengan bertambahnya usia anak. Ragammakanan yangdiberikan harus bergizi lengkap dan seimbang yang mana penting untuk menunjang tumbuh kembang danstatus gizi anak.

Menurut Soekirman (2000), menyatakan faktor yang mempengaruhi status gizi adalah kemiskinan, tingkat pendapatan keluarga, jumlah anggota keluarga, tingkat pendidikan, tingkat pengetahuan, sosial budaya dan bencana alam. Faktor lain yang mempengaruhi status gizi pada anak karena penghasilan rendah sehingga persediaan pangan tidak mencukupi dalam keluarga.

Hasil tabel diatas menunjukkan bahwa dari dari 34 anak yang berstatus ekonomi rendah terdapat $23(67.6 \%)$ yang berstatus gizi normal dan $11(32.3 \%)$ dengan status gizi tidak normal. Hasil uji Chi Square didapat $p$-Value $=0.011<\alpha$ 0,05 . Dengan demikian ada hubungan antara status ekonomi dengan status gizi pada anak sekolah dasar.

Hal ini sesuai dengan hasil penelitian yang dilakukan oleh oktari (2013) Penelitian ini mendapatkan hasil $8,21 \%$ siswa mengalami obesitas, $11,79 \%$ overweight atau gemuk, $82,60 \%$ tingkat pendapatan orang tua siswa berada di atas garis kemiskinan, $71,30 \%$ ayah dan $71,80 \%$ ibu siswa memiliki tingkat pendidikan menengah, 58,50\% siswa memiliki pola makan baik, dan $60 \%$ memiliki aktifitas fisik aktif. Tidak didapatkan hubungan yang bermakna antara kejadian status gizi dengan tingkat pendidikan orang tua (ayah: $\mathrm{p}=0,005$; ibu: $\mathrm{p}=1,00)$, tingkat pendapatan orang tua $(\mathrm{p}=0,396)$, dan pola makan anak ( $\mathrm{p}=0,245)$. Didapatkan hubungan yang bermakna antara aktifitas fisik anak dengan kejadian obesitas $(\mathrm{p}=0,048)$.

Menurut asumsi peneliti status ekonomi juga menjadi peran penting dalam kehidupan sehari-hari, untuk menghasilkan status gizi anak yang baik para orang tua harus dapat mengimbangi pendapatan nya yang rendah dengan kebutuhan gizi anak, anak usia sekolah sangat membutuhkan makanan yang bergizi, tetapi dari hasil penelitian yang peneliti dapatkan bahwa keluarga yg pendapatan rendah sebagian besar dapat mengimbangi pola makan yang bergizi, akan tetapi yang menjadi kendala adalah besar nya jumlah keluarga dan kurang nya perhatian keluarga sehingga tidak dapat mendampingi anak makan.

\section{KESIMPULAN}

Dari hasil penelitian yang di lakukan di SD Negeri Ulee Gle terhadap 62 responden dapat disimpulakan,yaitu :

1. Ada hubungan antara pola asuh dengan status gizi anak sekolah dasar dimana p-value $=0,009<0,05$

2. Ada hubungan status ekonomi dengan status gizi anak sekolah dasar dimana p-value $0,004<0,05$ 
Journal of Healthcare Technology and Medicine Vol. 2 No. 2 Oktober 2016

Universitas Ubudiyah Indonesia

e-ISSN : 2615-109X

DAFTAR PUSTAKA

Adisasmito W.sistem kesehatan. Jakarta : PT.Grafindo Persada: 2007

Almatsier S. Gizi Seimbang Dalam Daur Kehidupan.Jakarta: Gramedia: 2011

Arikunto. 2003.Dasar-Dasar Evaluasi Pendidikan.Bumi AksaraArisman, MB (2009) Buku Ajar Ilmu Gizi, Gizi Dalam Daur Kehidupan Edisi 2, EGC, Jakarta.

Badan Litbang Kesehatan,2010.Laporan hasil Riset Kesehatan Dasar Indonesia Tahun 2010,Jakarta:Kementrian kesehatan RI

Danuatmaja B, dkk.40 Hari pasca Persalinan.Jakarta : Puspa Swara: 2003

2002. Pemantauan Pertumbuhan Anak. Jakarta: Direktorat Gizi Masyarakat.

Gibney MJ, dkk. Gizi Kesehatan Masyarakat. Jakarta : Buku Kedokteran EGC:2009

Hadi.H.2005.Artikel Beban Ganda Masalah Gizi Dan Aplikasinya Terhadap Kebijakan Pembangunan Kesehatan Nasional.

Hastono Susanto Priyo,2007.Analisa Data Kesehatan, Depok. Fakultas Kesehatan Masyarakat Universitas Indonesia

Kementerian Kesehatan Republik Indonesia,2010.Keputusan Menteri Kesehatan RI.No.1995/Menkes/SK/XII/2010 tentang Standar Antropometri Penilaian Status Gizi Anak Sekolah Dasar

Khomsan A. 2004. Pangan dan Gizi Untuk Kesehatan 2. Bogor : Departemen Gizi Masyarakat, Fakultas Ekologi Manusia, institut Pertanian Bogor.

LIPI,2004 Angka Kecakupan Gizi Bagi Indonesia.Widyakarya Nasional Pangan Dan Gizi VIII.Jakarta

Moehyi s. Ilmu Gizi. Penanggulangan Gizi Buruk. Jakarta : Bharata Niaga Meda: 2003

Moersintowati,dkk. Tumbuh Kembang Anak dan Remaja Jilid I. Jakarta: buku Kedokteran EGC:2002

Najmah. Managemen \& Analisa Data Kesehatan. Yogyakarta : Nuha Medika. 2011

Notoatmojo, 1998. Ilmu Kesehatan Masyarakat. Rineka Cipta Jakarta ,2003.Pendidikan Dan Perilaku Kesehatan.Rineka Cipta Jakarta 2009. Metodelogi Penelitian Kesehatan. Rineka Cipta Jakarta

Sediaoetama AD. Ilmu Gizi Jilid I. Jakarta : Dian Rakyat: 2000

Soekirman,2000.Ilmu Gizi Dan Aplikasi Untuk Keluarga Dan Masyarakat.Jakarta Direktorat Tinggi Departemen Pendidikan Nasional

Soetjiningsih.Tumbuh Kembang Anak.Jakarta: Buku Kedokteran EGC : 2001

Tumbuh Kembang Remaja dan Permasalahannya.CV.Agung Seto 